\title{
Sources of dietary calcium in patients attending an osteoporosis clinic
}

\author{
This article was published in the following Dove Press journal: \\ Nutrition and Dietary Supplements \\ 17 September 2012 \\ Number of times this article has been viewed
}

\section{Gemma Horn \\ Surgical Department, Perth Royal Infirmary, Perth, Scotland}

Correspondence: Gemma Horn

Flat 637 Waterfront Park

Edinburgh EH5IEZ, Scotland

Tel +447970107865

Email gemmahorn@nhs.net
Introduction: Osteoporosis is a common disease that affects both women and men but is more prevalent in postmenopausal women. Reviews suggest that dietary-derived calcium is vital in maintaining adequate calcium balance. Sources of dietary calcium intake among adult patients attending an osteoporosis clinic were reviewed.

Method: Two hundred and ninety-one patients attending an osteoporosis clinic were given an eleven-item food questionnaire to complete. The results were compared to the recommended daily allowance of $700 \mathrm{mg}$.

Results: The overall mean intake was $657 \mathrm{mg} /$ day with little difference between age or gender. The best foods for supplying calcium were cheese and milky drinks.

Conclusion: This study has confirmed that suboptimal calcium intakes remain common. Dairy sources of calcium remain important. More awareness is needed to convey the importance of dietary calcium and bone health to avoid the development of osteoporosis.

Keywords: osteoporosis, clinic, food questionnaire, calcium, dietary intake, bone health

\section{Background}

Osteoporosis affects both men and women but it is particularly common in postmenopausal women. The prevalence of this disease increases with age. Dietary intake of calcium in adult premenopausal women has been positively associated with bone mineral density but is underutilized. ${ }^{3}$ Reviews suggest that dietary-derived calcium is vital in maintaining adequate calcium balance. ${ }^{1}$ This can also be supplemented with pharmacological derivatives. It has been suggested that postmenopausal women should aim for a dietary intake of $1000 \mathrm{mg}$ calcium per day as this can lead to a $24 \%$ reduction in hip fractures. ${ }^{2,4}$ This is higher than the $700 \mathrm{mg}$ recommended nutrient intake advised by the Committee on Medical Aspects of Food and Nutrition Policy. ${ }^{5}$ Since this study, the guidelines have been changed. The Institute of Medicine, Food and Nutrition Board has recently changed the recommended daily allowance for calcium to $1000 \mathrm{mg}$ /day, based on estimates of requirements of both genders throughout the life cycle. ${ }^{6}$ The tolerable upper limit has also been established for this nutrient as $2000 \mathrm{mg} /$ day. During several periods of the female life cycle, calcium intake is critical: prepuberty and adolescence, postmenopause, and during pregnancy and lactation. ${ }^{7}$ A previous study showed that increased dietary calcium intake protects against hip fracture. ${ }^{8}$ This hypothesis persisted after adjustment for cigarette smoking, alcohol intake, exercise, and obesity. Bones contain $99.5 \%$ of the total calcium in the body, and most of this is supplemented from food. ${ }^{9}$ 


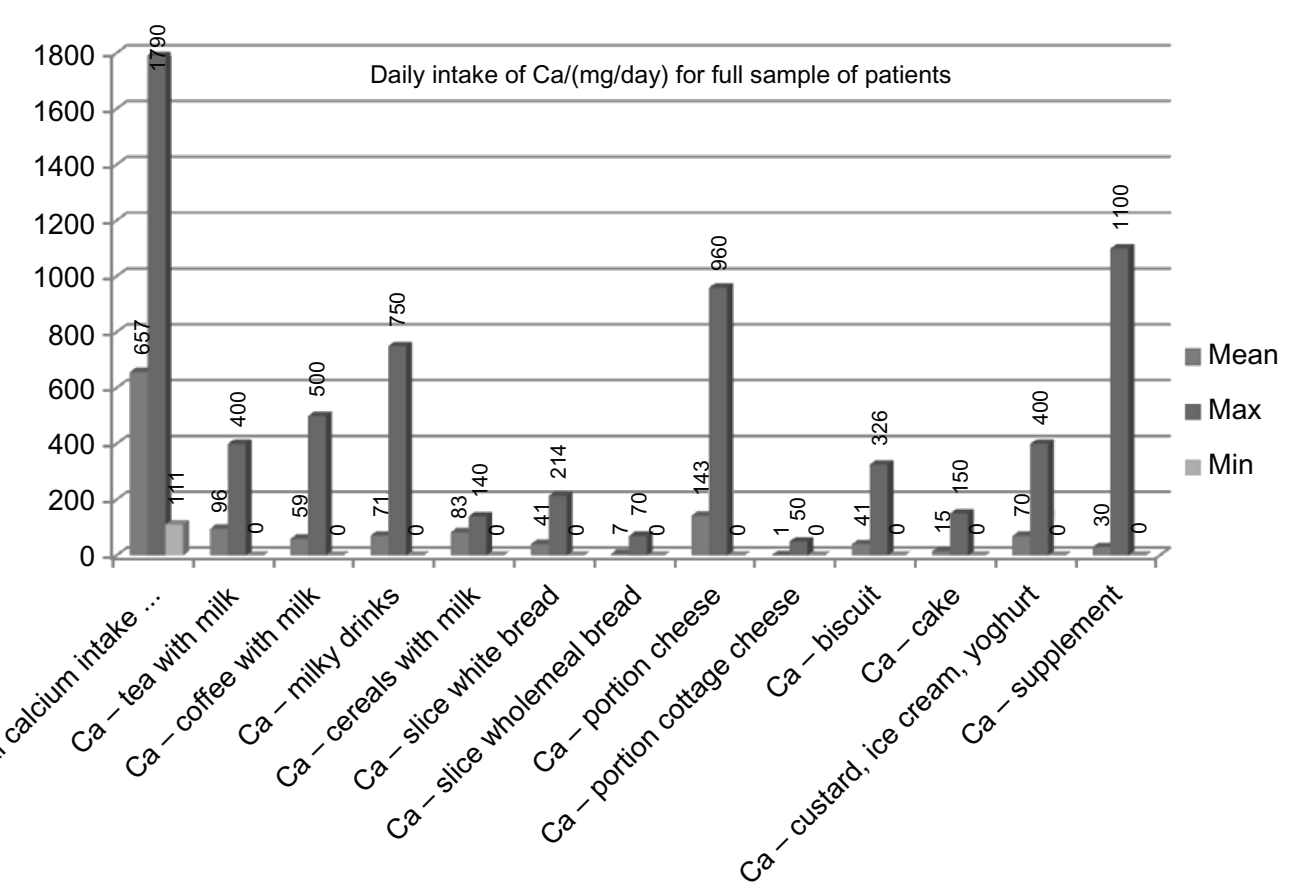

Figure I Daily calcium intake of all patients in the study $(n=291)$.

Abbreviation: $\mathrm{Ca}$, calcium.

A dietary source of calcium can come from many different food sources including milk, cheese, yogurt, and bread. ${ }^{10}$ Guidelines suggest that dietary-derived calcium is as effective as pharmacologically derived sources at maintaining adequate calcium balance. ${ }^{2}$
Recommended calcium intakes vary but should probably exceed $700 \mathrm{mg}$ of calcium daily in most adults. ${ }^{2}$ Many patients receive calcium supplements routinely (although adherence is poor), but there is concern that excess calcium supplements might contribute to vascular disease. ${ }^{11,12}$

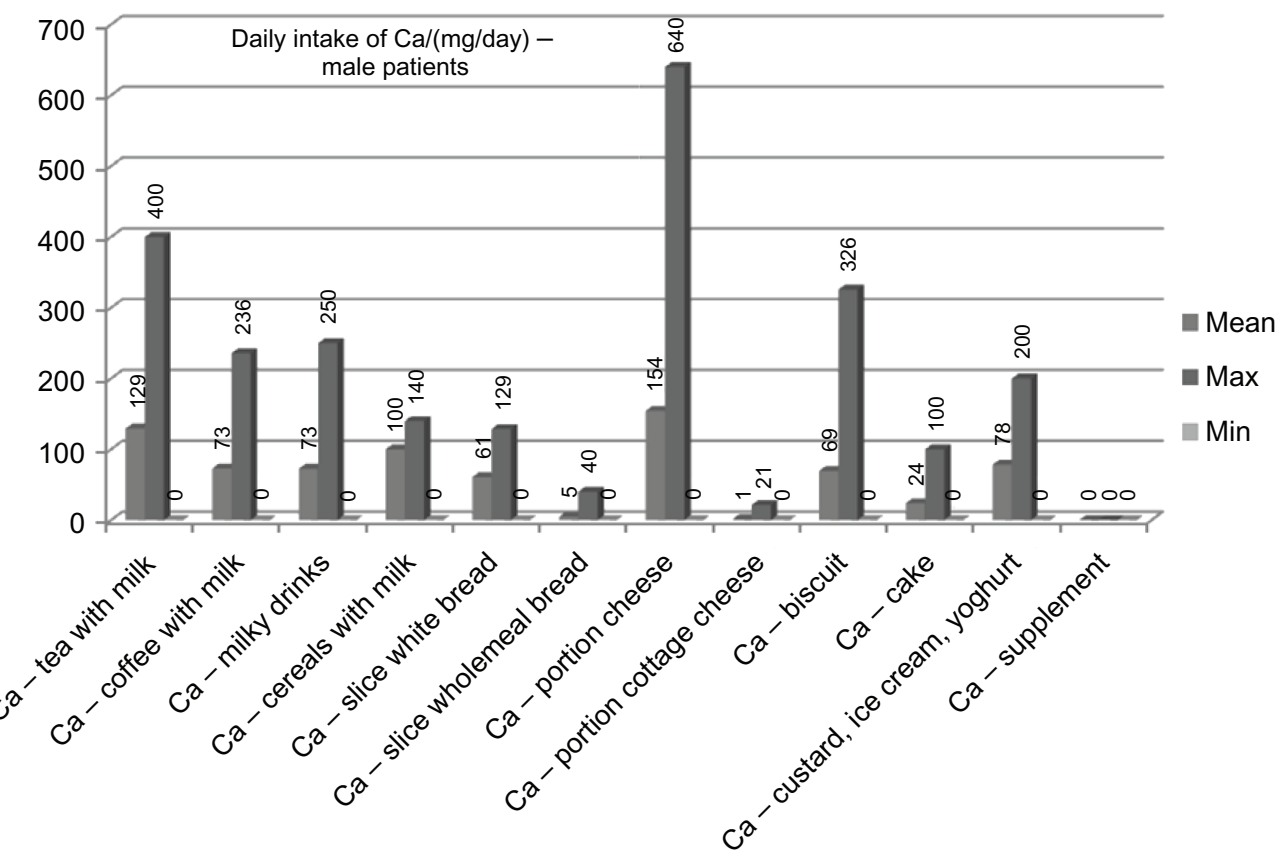

Figure 2 Daily calcium intake of male patients $(n=38)$.

Abbreviation: $\mathrm{Ca}$, calcium. 


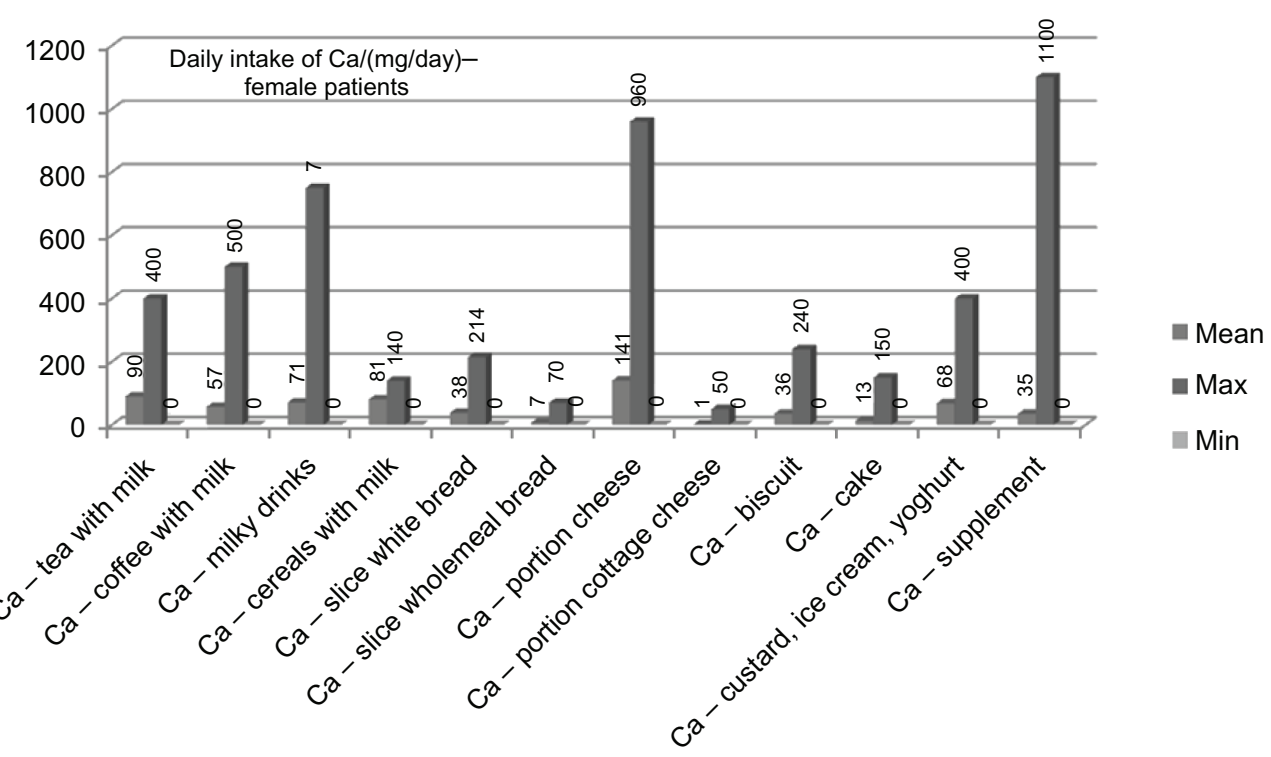

Figure 3 Daily calcium intake of female patients $(n=253)$.

Abbreviation: $\mathrm{Ca}$, calcium.

In this study, sources of dietary calcium intake among adult patients attending an osteoporosis clinic in Scotland were reviewed.

\section{Patients and methods}

This study included 291 (253 females) consecutive patients aged 22-97 years (mean age: 65 years) attending an osteoporosis

A

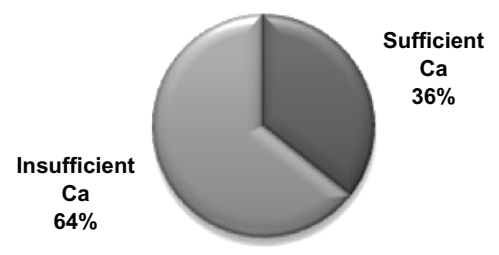

B

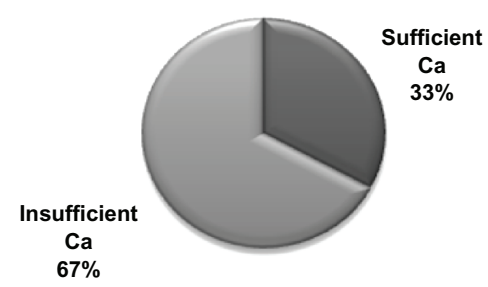

C

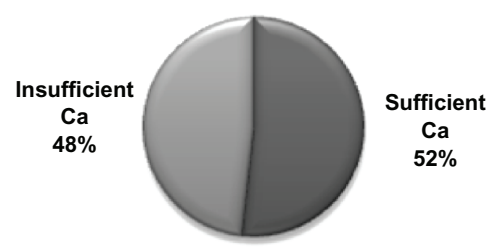

Figure 4 Percentage of $(\mathbf{A})$ all patients, $(\mathbf{B})$ females, and $(\mathbf{C})$ males receiving the correct amount of calcium ( $>700 \mathrm{mg}$ elemental calcium daily). clinic in Scotland over a period of 3 months in 2010. This timeline of clinic sessions was picked at random. Each patient attending the clinic completed an eleven-item food frequency questionnaire, which was validated by the rheumatology department. This was designed prior to the clinic visits and included common foods thought to be high in calcium by a group of consultants and junior doctors. The number of portions per week of foods rich in calcium was recorded for each patient as well as age and sex. Ethics approval was gained from the local hospital.

\section{Results}

The overall mean (standard deviation) total elemental calcium intake was 657 (305) mg/day (Figure 1), with $33 \%$ of females (Figure 2 ) and $52 \%$ of males (Figure 3 ) taking $>700 \mathrm{mg} /$ day. The source of calcium food composition data was taken from the United States Department of Agriculture National Nutrient Database for Standard Reference. ${ }^{10}$

More than half of the subjects $(64 \%)$ had a calcium intake of $<700 \mathrm{mg}$ daily, and only $11 \%$ consumed $>1 \mathrm{~g}$ daily (Figure 4).

The best foods for providing calcium are cheese, milky drinks, cereals with milk, and custard, ice cream, and yogurt (Figure 5). The portion size was defined from an average after discussion with patients (Table 1).

The top six calcium-providing food groups for the sample of patients were cheese, tea with milk, cereals with milk, 


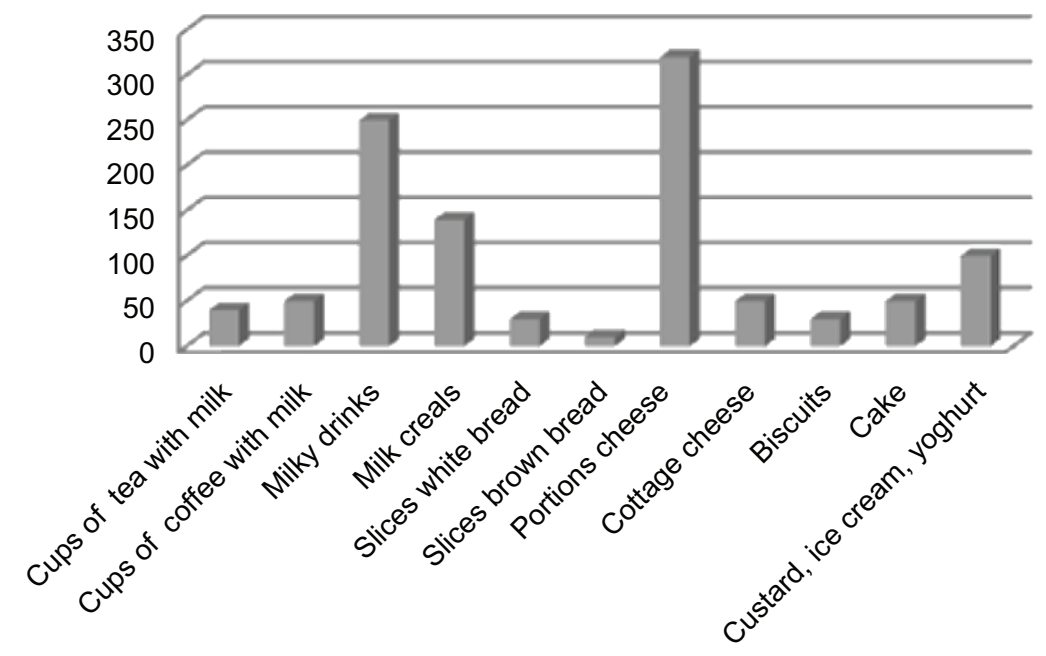

Calcium content (mg/portion)

Figure $\mathbf{5}$ The best sources of dietary calcium.

Table I The best foods for providing calcium and average portion size

\begin{tabular}{ll}
\hline Food group & Portion size \\
\hline Tea with milk & $30 \mathrm{~mL}$ \\
Coffee with milk & $30 \mathrm{~mL}$ \\
Milky drinks & $250 \mathrm{~mL}$ \\
Cereal with milk & $100 \mathrm{~mL}$ \\
Slice of white bread & I slice \\
Slice of brown bread & I slice \\
Portion of cheese & $30 \mathrm{~g}$ \\
Portion of cottage cheese & $40 \mathrm{~g}$ \\
Biscuits & I biscuit \\
Cake & I piece \\
Ice cream, yogurt, custard & I50 mL \\
\hline
\end{tabular}

milky drinks, custard, ice cream, and yoghurt, and coffee with milk (Figure 6).

The main source of calcium across all age groups in this study was from cheese, as it is a rich source of this element.

Calcium intake varied by age group with the $21-40$ and 81-100 year olds taking in more calcium than the 41-60 and 61-80 year olds (Figure 7). This may not be significant due to the reduced number of patients in the 81-100-year-old group.

\section{Discussion}

The selection of patients in this study may not be representative of the whole population in terms of their calcium

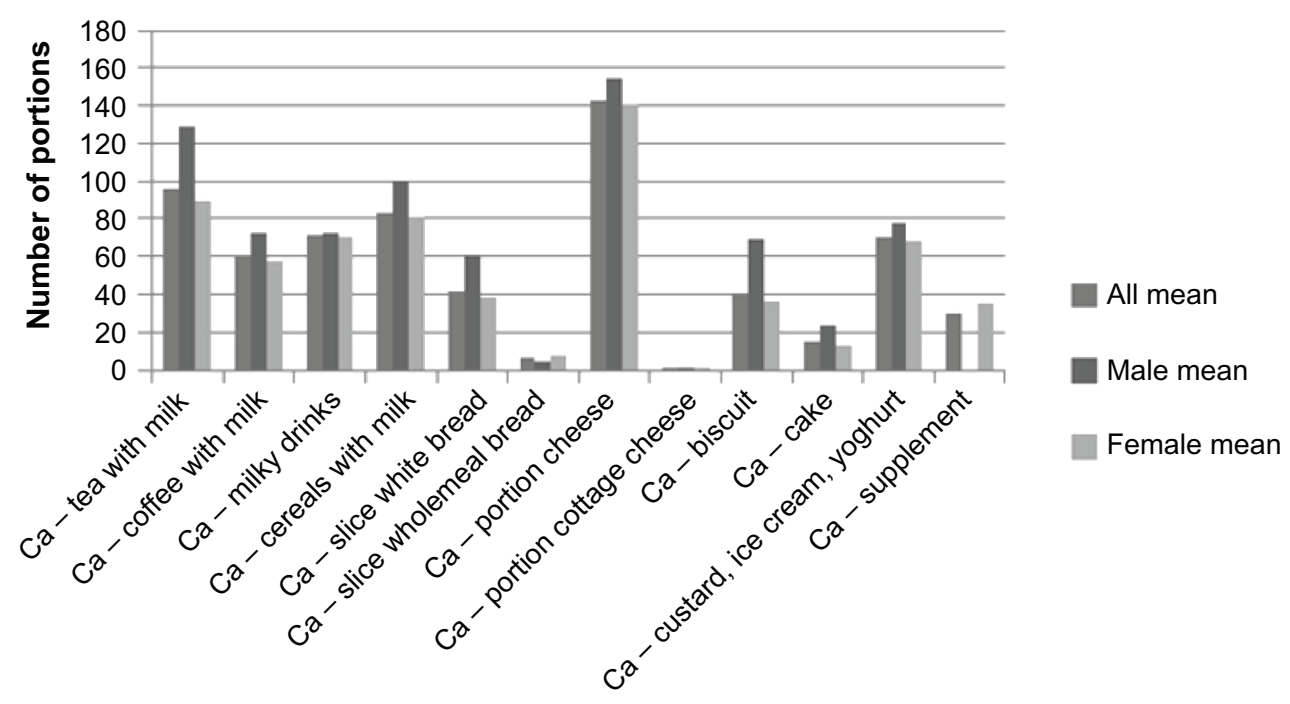

Figure 6 The source of calcium for all patients $(n=291)$.

Abbreviation: $\mathrm{Ca}$, calcium. 


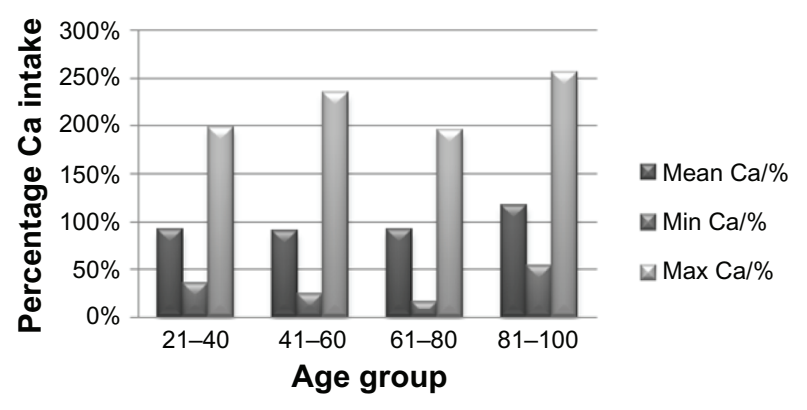

Figure 7 Calcium intake by age group.

Abbreviation: $\mathrm{Ca}$, calcium.

intake. As they are attending an osteoporosis clinic they may conceivably take less calcium, which is one of the reasons they have osteoporosis, or they are aware of their osteoporosis and they take more calcium. Therefore, this may not be an average representative. The food frequency questionnaire was a limitation in this research as it did not include questions about other sources of calcium such as nondairy. This was in order to make the questionnaire a reasonable length to enable it to be distributed at a clinic. Also, average portion sizes were used, which may differ from patient to patient.

An area of interest in this study is the fact that most calcium intake was from cheese. This may affect cardiovascular health. Therefore, healthier options could be advised to patients such as broccoli or fish. It was noted that patients drink a lot of milk in caffeinated beverages. It is also unfortunate that the antioxidant benefits of tea are attenuated by the addition of milk, along with the absorption of calcium..$^{13,14}$

Results from other studies have similarly shown a lack of dietary calcium intake throughout the population and an increased intake of cheese. ${ }^{15,16}$ More awareness is needed and more advice should be given to patients about the importance of calcium intake in relation to osteoporosis and the beneficial healthy sources of calcium available.

\section{Conclusion}

This study has highlighted that suboptimal calcium intakes remain common; although universal calcium supplementation according to guidelines is not always required. ${ }^{2}$ Dairy sources of calcium remain important. Dietary intake does not differ between gender, with the main source of calcium being from cheese. Future studies should include estimates of potentially healthier sources of calcium such as broccoli, almonds, and bony fish. ${ }^{10}$ In conclusion, more awareness about the importance of dietary calcium and bone health is needed to avoid the development of osteoporosis.

\section{Acknowledgments}

The author would like to thank the rheumatology department in Perth Royal Infirmary (Perth, Scotland) and Dr Garton for overseeing this research. The author would also like to thank the patients who took the time to complete the questionnaire in the clinic.

\section{Disclosure}

The author reports no conflicts of interest in this work.

\section{References}

1. Horn G. Sources of dietary calcium in an osteoporosis clinic. Paper presented at: Osteoporosis Conference; November 28-December 1, 2010; Liverpool, United Kingdom.

2. Scottish Intercollegiate Guidelines Network. Guideline 71. Management of Osteoporosis: A National Clinical Guideline. Edinburgh: Scottish Intercollegiate Guidelines Network; 2003.

3. Feldstein AC, Nichols G, Orwoll E, et al. The near absence of osteoporosis treatment in older men with fractures. Osteoporos Int. 2005;16(8): 953-962.

4. Cumming RG, Nevitt MC. Calcium for prevention of osteoporotic fractures in postmenopausal women. J Bone Miner Res. 1997;12(9): 1321-1329.

5. Calman K, Aggett PJ; Committee on Medical Aspects of Food and Nutrition Policy, Department of Health. Nutrition and Bone Health: with Particular Reference to Calcium and Vitamin D. London: The Stationery Office; 1998.

6. Institute of Medicine. Dietary Reference Intakes for Calcium and Vitamin D. Washington, DC: National Academies Press; 2010.

7. Institute of Medicine. Dietary Reference Intakes for Calcium and Vitamin D. Washington, DC: National Academies Press; 2005.

8. Holbrook TL, Barrett-Connor E, Wingard DL. Dietary calcium and risk of hip fracture: 14-year prospective population study. Lancet. 1988;2(8619): 1046-1049.

9. Camacho PM, Rehan KM. The role of calcium and vitamin d in bone health: nutrients for osteoporosis prevention. In: Endocrineweb [website on the Internet]. March 22, 2012. Available from: http://www. endocrineweb.com/conditions/osteoporosis/role-calcium-vitamind-bone-health\#The_following_chart_shows. Accessed August 1, 2012.

10. United States Department of Agriculture. National Nutrient Database for Standard Reference. December 7, 2011. Available from: http://www.ndb. nal.usda.gov. Accessed August 1, 2012.

11. Shah SM, Carey IM, Harris T, De Wilde S, Cook DG. Calcium supplementation, cardiovascular disease and mortality in older women. Pharmacoepidemiol Drug Saf. 2010;19(1):59-64.

12. Hsia J, Heiss G, Ren H, et al. Calcium/vitamin D supplementation and cardiovascular events. Circulation. 2007;115(19):846-854.

13. Chacko SM, Thambi PT, Kuttan R, Nishigaki I. Beneficial effects of green tea: a literature review. Chin Med. 2010;5:13.

14. Gray C. Tea and calcium absorption. In: Livestrong.com [website on the internet]. March 29, 2011. Available from: http://www.livestrong. com/article/292166-tea-and-calcium-absorption/. Accessed June 27, 2012.

15. Cummings SR, Block G, McHenry K, Baron RB. Evaluation of two food frequency methods of measuring dietary calcium intake. Am J Epidemiol. 1987;126(5):796-802.

16. Musgrave KO, Giambalvo L, Leclerc H, Cook RA, Rosen CJ. Validation of a quantitative food frequency questionnaire for rapid assessment of dietary calcium intake. J Am Diet Assoc. 1989;89(10): 1484-1488. 


\section{Publish your work in this journal}

Nutrition and Dietary Supplements is an international, peer-reviewed, open access journal focusing on research into nutritional requirements in health and disease, impact on metabolism and the identification and optimal use of dietary strategies and supplements necessary for normal growth and development. The journal welcomes papers covering

original research, basic science, clinical \& epidemiological studies, reviews and evaluations, guidelines, expert opinion and commentary, case reports and extended reports. The manuscript management system is completely online and includes a very quick and fair peer-review system, which is all easy to use.

Submit your manuscript here: http://www.dovepress.com/nutrition-and-dietary-supplements-journal 